Review Article

\title{
Rapid Maxillary Expansion and Nocturnal Enuresis in Children and Adolescents: A Systematic Review of Controlled Clinical Trials
}

\author{
Khaled Khalaf $(\mathbb{D}$, Dina Mansour, Zain Sawalha, and Sima Habrawi \\ Department of Preventive and Restorative Dentistry, University of Sharjah, Sharjah, UAE \\ Correspondence should be addressed to Khaled Khalaf; kkhalaf@sharjah.ac.ae
}

Received 7 April 2021; Revised 12 May 2021; Accepted 25 May 2021; Published 3 June 2021

Academic Editor: Carlo Eduardo Medina-Solis

Copyright (C) 2021 Khaled Khalaf et al. This is an open access article distributed under the Creative Commons Attribution License, which permits unrestricted use, distribution, and reproduction in any medium, provided the original work is properly cited.

\begin{abstract}
Objectives. To evaluate the effectiveness of rapid palatal expansion in the treatment of nocturnal enuresis among 6-18-year-old children and adolescents. Methods. Comprehensive searches were carried out in 6 electronic databases (EBSCO, ProQuest, Clinical Key, Science Direct, SCOPUS, and OVID) and supplemented by additional manual searches in 4 orthodontic journals until June 2020. Randomized controlled clinical trials (RCTs) and controlled clinical trials (CCTs) of children and adolescents aged 6-18 years old of both genders who underwent rapid palatal expansion and were considered unresponsive to previous conventional nocturnal enuresis treatment were included in this review. Risk of bias of individual trials was assessed using the Risk of Bias in Non-randomized Studies of Interventions (ROBINS-I) assessment tool for CCTs and the revised Cochrane Risk-of-Bias tool for RCTs (RoB 2). Results. Four studies met all inclusion criteria and were finally included in this systematic review, of which one was an RCT and three were CCTs. Reduction in nocturnal enuresis frequency was reported in all included studies with varying rates and methods of reporting, but most studies reported a statistically significant reduction in the number of wet nights per week. The average range of becoming completely dry 1 year after treatment with an RME was $0 \%-60 \%$. Also, there was a statistically significant correlation between an improvement in bedwetting and an increase in nasal volume after the use of RME. Conclusion. A rapid palatal expansion device may be considered as an alternative treatment option of the nocturnal enuresis condition with guarded prognosis when other treatment modalities have failed.
\end{abstract}

\section{Introduction}

Nocturnal enuresis (NE) or bedwetting (BW) is a prevalent condition that affects around $10 \%$ of children around the world, making it the second most common problem in school aged children after asthma and allergies [1-3]. It is defined as the involuntary voiding of urine by distinct acts of micturition at night in children 5 years old and above and is more common in males than females [4].

Monosymptomatic nocturnal enuresis is defined as the absence of or subtle daytime symptoms; presents $80 \%$ of cases with NE. Furthermore, cases can be classified into either primary (children who never achieved dryness) or secondary (dryness has been achieved for at least six months before enuresis begins) [5]. On the brighter side, NE is reported to have annual spontaneous cure rate of 15\% [6]. Rarely, approximately in $0.5 \%$ to $2 \%$ of cases, NE persists in otherwise-healthy adults [7]. It is important to distinguish between NE and nocturia which is defined as the frequent night awakening to void [8].

The pathogenesis of NE is considered to be multifactorial and complex. However, previous studies were able to clear some ambiguities and highlight some important factors linked to this disorder. Historically, bedwetting was regarded a psychiatric disorder. Over the years, a clearer understanding has been obtained and causative factors have been narrowed down to mainly three reasons: (1) excessive production of urine at night, (2) hyperactivity of the bladder's smooth muscle, and (3) the inability to wake while asleep to empty the bladder when full. Furthermore, it has been reported in some patients that enuresis can be caused by a blockage of the upper airway [9].

Surprisingly, numerous "enuresis genes" have been detected making this disorder is highly hereditary, with 
astonishing increase in risk of $5-7 \%$ if one parent was affected [10]. Bedwetting is a stressful condition that has a negative impact on the child's quality of life during their development; such drawbacks can immensely improve with successful treatment [11].

Results obtained from multiple meta-analyses and clinical trials proposed different treatment modalities for children with NE $[5,9,11,12]$. Such interventions usually start at the onset of the problem which is around 5-6 years of age. Generally, treatment options include motivational therapy, bladder training, fluid management, night alarms, and pharmacological agents such as desmopressin and tricyclic antidepressants. However, evidence is mostly in favor of the enuresis alarm which is considered the most effective and lasting management approach as has been shown in a systematic review of a large number of clinical trials (56). The second most accepted treatment option is the use of desmopressin or imipramine, an analogue of the vasopressin hormone, which reduces the production of urine and has been in use in the medical field for many years $[11,12]$.

The current treatment modalities provide results that are far from satisfactory and have been proven by various trials to have minimal efficacy in the management of this condition. Therefore, investigators have started focusing on alternative treatment options. According to several case reports, there seems to be a correlation between the resolution of upper airway blockage and an improvement in the condition of NE, since up to $80 \%$ of enuretic children have concurrent sleep apnea [13]. From this point, several other treatment options were described for the treatment of sleep disordered breathing and airway obstruction. The most common treatment proposed was adenotonsillectomy, to reduce nocturnal resistance airflow, therefore alleviating NE [14].

Some studies have reported the use of rapid maxillary expansion as a treatment modality to treat NE [14-16]. Expansion of approximately $5 \mathrm{~mm}$ was achieved by applying an orthodontic device to increase the maxillary width within $10-14$ days $[17,18]$. However, it is not yet known how effective this form of intervention to treat young children with NE who were unresponsive to the commonly used treatment modalities.

Therefore, the aim of our systematic review was to investigate whether a rapid maxillary expansion is an effective management approach in alleviating or treating nocturnal enuresis of young children and adolescents who were unresponsive to the commonly used treatment modalities.

\section{Materials and Methods}

2.1. Protocol and Registration. This systematic review was executed using the Prisma checklist guidelines and registered in PROSPERO (International Prospective Register of Systematic Reviews) under the registration number CRD42020170752.

2.2. Information Sources and Search Strategy. A comprehensive search strategy was performed using both manual and electronic sources to identify and include all potential articles. The electronic database search included the following databases: EBSCO (January 1990-June 2020), ProQuest (January 1998-June 2020), Clinical Key (October 1990-June 2020), Science Direct (June 1945-June 2020) SCOPUS (1990-2020), and OVID (1990-June 2020).

The manual search included the following journals: American Journal of Orthodontics and Dentofacial Orthopedics [AJODO] (July 1986-June 2020), Journal of orthodontics [JO] (March 2003-June 2020), Angle Orthodontist [AO] (January 1931-June 2020), and European Journal of Orthodontics [EJO] (February 1996-June 2020).

A combination of medical and non-medical terms were used for searching the electronic databases; terms included "rapid maxillary expansion", "rapid palatal expansion," "rapid expander", "maxillary expansion", "nocturnal enuresis", "bedwetting", and "children" and "adolescents". Search terms were adapted to each electronic database to identify all potential articles indexed in the database.

2.3. Selection of Studies. Following a comprehensive search, only studies fulfilling the following criteria were included in this systematic review: (1) children and adolescents of either gender with 6-18 years old, (2) diagnosed with either primary or secondary therapy resistant NE, (3) had rapid maxillary expansion to treat nocturnal enuresis as the main outcome, and (4) were followed for at least six months post expansion. Papers that were reported in non-English or included participants with heavy snoring, sleep apnea, untreated constipation, concurrent urological, endocrinological, nephrological, odonatological or psychiatric disorders, and children and adolescents involved in ongoing enuretic treatment were excluded. Furthermore, study design was limited to only randomized controlled clinical trials and controlled clinical trials.

The PICOs components used in this systematic review were as follows:

Population: children and adolescents of either gender aged 6-18 years old who were diagnosed with either primary or secondary therapy resistant NE.

Intervention: rapid maxillary expansion device to expand the maxilla.

Comparison: no expansion of the maxilla/passive rapid maxillary expansion device.

Primary outcome measure: the number of wet nights per week.

Secondary outcome measures: the number of responders, intermediate responders, and non-responders; cure rate (complete dryness) in the shortterm (one month, 3 months and 6 months) and in the log-term (one year and 3 years); nasal volume after the use of RME.

Study design: randomized controlled clinical trials (RCCTs) and controlled clinical trials (CCTs).

Titles, abstracts, and finally full texts of possible articles were scrutinized. Furthermore, references of the identified 
full text studies were inspected to identify additional ones for inclusion in the systematic review. The electronic and hand search was carried out in duplicate by two teams of investigators who met thereafter and had to agree. In the case of disagreement, a third author was consulted to reach a final decision.

2.4. Data Extraction. A form was created and used to extract all relevant information from the final included articles. The extraction of data was performed in duplicate to ensure accuracy of information gathered. For each article included, participant's demographic data, frequency of NE, signs and symptoms of upper airway obstruction (e.g., snoring, open mouth during sleep, and sleep apnea), Angle's classification, presence of crossbites, daily palatal expansion, duration of expansion, type of appliance used, expansion end point, study methodology, response rates (i.e., responders, partial responders, and non-responders), time to become completely dry or improved, follow-up periods and enuresis type (i.e., primary or secondary), and type of statistical analysis used (if any) were gathered (Table 1).

2.5. Risk of Bias of Individual Trials. Two investigators independently assessed the risk of bias of the included articles using suitable assessment tools. Any disagreement between the two investigators was settled by a third author. Nonrandomized clinical trials were assessed using the Risk of Bias in Non-randomized Studies of Interventions (ROBINSI) assessment tool [19]. On the other hand, randomized clinical trials were assessed using the revised Cochrane Riskof-Bias tool for randomized trials (RoB 2) [20].

2.6. Data Synthesis Strategy. Data from the included studies will ideally be analyzed quantitatively using a meta-analysis if deemed appropriate, i.e., all included studies are homogenous in terms of study design and outcome measures reported and all are of low risk of bias; otherwise a descriptive (narrative) analysis will be carried out.

2.7. Assessment of Quality of Evidence Presented by This Review. Quality of evidence presented by this review was assessed using the GRADE approach (Grading of Recommendations Assessment, Development, and Evaluation) [21]. It consists of five assessment domains: risk of bias, inconsistency, imprecision, indirectness, and publication bias. A rating grade of high, moderate, low, or very-low is given to the quality of evidence presented by the review based on the above domains.

\section{Results}

3.1. Samples and Intervention Characteristics. Figure 1 shows the process of identifying and selecting all suitable articles for inclusion in this review. In total, 195 articles were assessed, of which 150 were from the online databases, and 45 from the manual search. Thirty-nine studies were duplicates, and 143 were not relevant from their abstracts and titles, thus leaving 13 articles deemed suitable at this stage for the inclusion in this review. Following probing the full texts of these studies, 9 were excluded, of which 5 were case series, 1 was not in English, 2 included adult patients, and 1 was duplicate of another study. Thus, only four studies were finally included in this systematic review, of which one was a randomized clinical trial (RCT) and three were non-randomized clinical trials (CCTs). One of these CCTs was published as two separate articles and thus were considered as one study in this systematic review. Two of the three CCTs used the expansion appliance as a placebo and one study had a separate control group.

The agreement between the reviewers regarding searching, identifying, and selecting the final studies was assessed using a kappa statistic which was found to be 0.89 .

In total, the number of participants in the studies included was 129 children and adolescents (3 dropped out) with an age range of 6 to 18 years. Descriptive and demographic data are presented in Table 1. All studies used a hyrax screw which was inserted in an acrylic expanding device; some studies used a sham device for placebo effect. Expansion was achieved by applying a rapid heavy force delivered to the mid palatal suture by turning the screw twice/day. Expansion caused the suture to distract and the two palatal shelves to be pushed apart causing a diastema between the central incisors [22]. The expansion device was kept in place for a few months after finishing the active phase (10-14 days) as a retainer and to prevent further collapse.

3.2. Risk of Bias within Studies. Figures 2 and 3 show the risk of bias judgement for the final studies with the tools used and a justification for the grade given for each study. Two of the three CCTs [23-25] were assessed at moderate risk of bias and one at serious risk of bias [27], whereas the RCT [26] was assessed to be at low risk of bias.

3.3. Results of Individual Studies. Results of the individual studies will be summarized and reported narratively as it was not possible to pool the findings in a meta-analysis approach due to the heterogeneity among the included studies in terms of study design and outcome measures reported and all but one study being of at least moderate risk of bias.

3.3.1. Improvement in Nocturnal Enuresis. Reduction in nocturnal enuresis was reported in all included studies with varying rates and methods of reporting such an improvement. Three studies $[23,24,27]$ reported a reduction in NE frequency and presented their findings in terms of responders (patients who became completely dry), intermediate responders (patients who still wet the bed occasionally), and non-responders (patients who did not improve and wet the bed regularly). Ring et al. [26] reported a statistically significant decrease in the number of wet nights during 2 weeks following the treatment with an RME $(p<0.001)$, but no significant decrease was found following the placebo treatment $(p>0.40)$. The mean number of wet nights per 2 weeks has significantly declined from 11.9 to 8.5 , 
TABLE 1: Summary data of the included studies.

\begin{tabular}{|c|c|c|c|c|c|c|c|}
\hline $\begin{array}{l}\text { Author, } \\
\text { year of } \\
\text { study }\end{array}$ & Study type & Participants & $\begin{array}{c}\text { Inclusion and } \\
\text { exclusion criteria }\end{array}$ & $\begin{array}{l}\text { Intervention/ } \\
\text { control }\end{array}$ & $\begin{array}{c}\text { Amount of } \\
\text { expansion }\end{array}$ & $\begin{array}{l}\text { Follow-up } \\
\text { periods }\end{array}$ & Findings of the study \\
\hline $\begin{array}{l}\text { Neveus } \\
\text { et al., } 2014 \\
\text { and } \\
\text { Bazargani } \\
\text { et al., } 2016 \\
\text { (one study } \\
\text { published as } \\
\text { two separate } \\
\text { articles) }\end{array}$ & $\begin{array}{l}\text { Nonrandomized } \\
\text { controlled trail }\end{array}$ & $\begin{array}{l}\text { (i) } 34(29 \mathrm{M} \text {, } \\
5 \mathrm{~F}) \text {, one } \\
\text { dropped out }\end{array}$ & $\begin{array}{l}\text { (i) Inclusion criteria: } \\
\text { children did not } \\
\text { respond to } \\
\text { conventional } \\
\text { treatments }\end{array}$ & $\begin{array}{l}\text { RME appliance } \\
\text { activated for all } \\
\text { patients/RME } \\
\text { appliance was } \\
\text { left passive for } \\
\text { the initial } 4 \\
\text { weeks for all } \\
\text { patients }\end{array}$ & $\begin{array}{l}0.5 \mathrm{~mm} \\
\text { daily } \\
(0.25 \mathrm{~mm} \\
\text { morning, } \\
0.25 \mathrm{~mm} \\
\text { night })\end{array}$ & $\begin{array}{l}\text { (ii) With the } \\
\text { orthodontic } \\
\text { appliance in } \\
\text { situ } \\
\text { (iii) } 6 \text { months } \\
\text { (after } \\
\text { completion } \\
\text { of expansion) } \\
\text { (iv) } 1 \text { year } \\
\text { post } \\
\text { treatment }\end{array}$ & $\begin{array}{l}\text { (i) The number of wet } \\
\text { nights/week on the } 4 \\
\text { follow-up periods } \\
\text { was } 5.48 \pm 1.48 \text {, } \\
5.12 \pm 1.73 \text {, } \\
3.09 \pm 2.49 \text {, and } \\
2.63 \pm 2.81 ; p \\
<0.001 \\
\text { (ii) After RME the } \\
\text { number of } \\
\text { responders and } \\
\text { intermediate } \\
\text { responders was } 16 / 33 \\
\text { (48.5\%), and the } \\
\text { number of } \\
\text { nonresponders was } \\
17 / 33 \text { (51.5\%) } \\
\text { (iii) The long-term } \\
\text { cure rate after } 1 \text { year } \\
\text { was } 18 / 30 \text { ( } 60 \% \text { ), } \\
\text { whereas } 12 / 30 \text { ( } 40 \%) \\
\text { had no long-term } \\
\text { response } \\
\text { (iv) Nonresponders } \\
\text { had more frequent } \\
\text { enuresis }(6.29 \pm 1.31 \\
\text { versus } 4.63 \pm 1.15 \text { wet } \\
\text { nights/week; } p \\
=0.001)\end{array}$ \\
\hline $\begin{array}{l}\text { Al-Taai } \\
\text { et al., } 2015\end{array}$ & $\begin{array}{l}\text { Nonrandomized } \\
\text { controlled trial }\end{array}$ & $\begin{array}{l}\text { (ii) Age: 6-15 } \\
\text { years }\end{array}$ & $\begin{array}{l}\text { (i) Inclusion criteria: } \\
\text { healthy children with } \\
\text { monosymptomatic } \\
\text { primary NE (MPNE) } \\
\text { treated with Minirin } \\
\text { without long-term } \\
\text { improvement }\end{array}$ & $\begin{array}{l}\text { RME appliance } \\
\text { activated for all } \\
\text { patients/RME } \\
\text { appliance was } \\
\text { left passive for } \\
\text { the initial } 30 \\
\text { days for } 7 \\
\text { patients }\end{array}$ & $\begin{array}{l}0.45 \mathrm{~mm} \\
\text { per day }\end{array}$ & $\begin{array}{l}\text { (i) } 2-3 \\
\text { months after } \\
\text { RME }\end{array}$ & $\begin{array}{l}\text { (i) The mean value of } \\
\text { wetting per night } \\
\text { before } \\
\text { expansion = } 2.21 \\
\text { (ii) The mean value of } \\
\text { wetting per night } 2-3 \\
\text { months after } \\
\text { RME = } 0.42 \\
\text { (iii) } 30 \text { days after } \\
\text { RME expansion, } 6 \\
\text { out of } 12 \text { children } \\
\text { demonstrated } \\
\text { complete dryness, } \\
\text { and the remaining } \\
\text { demonstrated an } \\
\text { improvement of NE } \\
\text { (iv) No significant } \\
\text { impact on NE ( } p \\
>.05 \text { ) was found in } \\
\text { the control group ( } 7 \\
\text { patients) } 30 \text { days } \\
\text { after the use of a } \\
\text { passive RME device } \\
\text { (v) After } 3 \text { years, all } \\
\text { patients reported } \\
\text { complete dryness }\end{array}$ \\
\hline
\end{tabular}


TABle 1: Continued.

\begin{tabular}{|c|c|c|c|c|c|c|c|}
\hline $\begin{array}{l}\text { Author, } \\
\text { year of } \\
\text { study }\end{array}$ & Study type & Participants & $\begin{array}{l}\text { Inclusion and } \\
\text { exclusion criteria }\end{array}$ & $\begin{array}{l}\text { Intervention/ } \\
\text { control }\end{array}$ & $\begin{array}{l}\text { Amount of } \\
\text { expansion }\end{array}$ & $\begin{array}{l}\text { Follow-up } \\
\text { periods }\end{array}$ & Findings of the study \\
\hline $\begin{array}{l}\text { Hyla-Klekot } \\
\text { et al., } 2015\end{array}$ & $\begin{array}{c}\text { Nonrandomized } \\
\text { control trial }\end{array}$ & $\begin{array}{l}\text { (ii) Age: 6-18 } \\
\text { years } \\
\text { (iii) } 16 \\
\text { experimental } \\
(9 \mathrm{M}, 7 \mathrm{~F} \text { ) } \\
\text { (iv) } 25 \mathrm{control} \\
\text { (15 M, } 10 \mathrm{~F} \text { ) }\end{array}$ & $\begin{array}{l}\text { (ii) Exclusion criteria: } \\
\text { active dental caries, } \\
\text { bad oral hygiene, } \\
\text { inadequate number of } \\
\text { teeth for fitting the } \\
\text { appliance, and lack of } \\
\text { cooperation with } \\
\text { orthodontic treatment }\end{array}$ & $\begin{array}{c}\text { RME activated } \\
\text { (16)/No RME } \\
\text { (25) }\end{array}$ & $\begin{array}{l}\text { Total of } \\
6.5 \mathrm{~mm}\end{array}$ & $\begin{array}{l}\text { (i) Every } \\
\text { month } \\
\text { during the } \\
\text { first } 12 \\
\text { months }\end{array}$ & $\begin{array}{l}\text { (i) } 10 / 16 \text { children in } \\
\text { the intervention } \\
\text { group did not wet the } \\
\text { bed at all after } 3 \\
\text { months and this was } \\
\text { maintained } 3 \text { years } \\
\text { later ( } 8 / 16 \text { children } \\
\text { remained dry) } \\
\text { (ii) After } 3 \text { years, } 50 \% \\
\text { of the children in the } \\
\text { intervention group } \\
\text { were completely dry } \\
\text { compared with only } \\
32 \% \text { in the control } \\
\text { group } \\
\text { (iii) After } 3 \text { years, } \\
\text { there was } 4.5 \text { times } \\
\text { increase in the } \\
\text { reduction of NE in } \\
\text { the experimental } \\
\text { group compared with } \\
\text { the control group }\end{array}$ \\
\hline $\begin{array}{l}\text { Jönson Ring } \\
\text { et al., } 2019\end{array}$ & $\begin{array}{l}\text { Randomized } \\
\text { clinical trail }\end{array}$ & $\begin{array}{l}\text { (i) In total } 38,2 \\
\text { dropped out } \\
\text { from the } \\
\text { placebo group, } \\
\text { age: } 10.2 \pm 1.8\end{array}$ & $\begin{array}{l}\text { (i) Inclusion criteria: } \\
\text { primary NE with at } \\
\text { least } 7 \text { wet nights } \\
\text { fortnightly and } \\
\text { nonresponders to } \\
\text { first-line treatment }\end{array}$ & $\begin{array}{l}\text { RME appliance } \\
\text { activated for } 2 \\
\text { weeks/RME } \\
\text { appliance was } \\
\text { left passive for } \\
\text { the } 2 \text { weeks }\end{array}$ & $\begin{array}{c}0.5 \mathrm{~mm} \text { per } \\
\text { day }\end{array}$ & $\begin{array}{l}\text { (iii) } 6 \text { months } \\
\text { (T3) }\end{array}$ & $\begin{array}{l}\text { (i) From T0 to T1, the } \\
\text { experimental group } \\
\text { demonstrated a } \\
\text { significant reduction } \\
\text { of wet nights (mean } \\
\text { difference = -2.2) } \\
\text { and the placebo } \\
\text { group demonstrated } \\
\text { no significant } \\
\text { reduction of wet } \\
\text { nights, mean } \\
\text { difference }=-0.6 \text { ). } \\
\text { The difference } \\
\text { between the } 2 \text { groups } \\
\text { was not statistically } \\
\text { significant } \\
\text { (ii) The mean } \\
\text { reduction of wet } \\
\text { nights for the whole } \\
\text { group } 6 \text { months after } \\
\text { expansion was } \\
\text { significant (mean } \\
\text { difference =-3.2) } \\
\text { (iii) } 11 \text { patients ( } 35 \% \text { ) } \\
\text { had a reduction in the } \\
\text { frequency of NE by } \\
>50 \% \\
\text { (iv) At } 6 \text { months, the } \\
\text { number of full, } \\
\text { intermediate, and } \\
\text { nonresponders was } 1 \text {, } \\
10 \text {, and } 20 \text {, } \\
\text { respectively } \\
\text { (v) A wide maxilla } \\
\text { and great voided } \\
\text { volumes at baseline } \\
\text { may be associated } \\
\text { with a reduced } \\
\text { frequency of enuresis }\end{array}$ \\
\hline
\end{tabular}

M: male, F: female, NE: nocturnal enuresis, RME: rapid maxillary expansion, NE: nocturnal enuresis. 


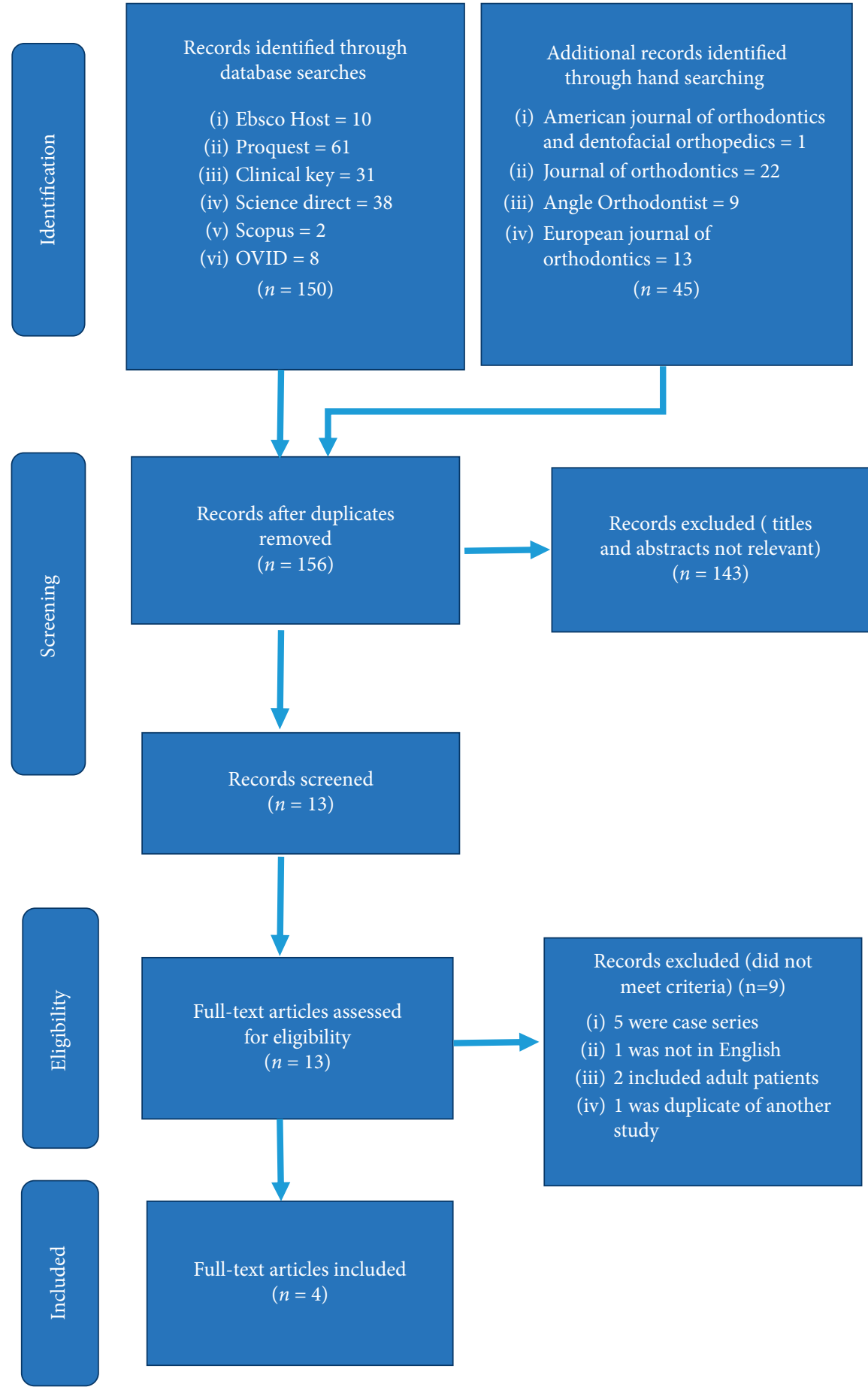

FIGURE 1: Flowchart of identifying, screening, and selecting suitable studies using Preferred Reporting Items for Systematic Reviews and Meta-Analyses (PRISMA).

which was translated as one full responder, 10 intermediate responders, and 20 non-responders. However, the difference between the intervention and control groups was not statistically significant [26]. On the other hand, Bazargani et al. [23] and Nevéus et al. [24] reported a statistically significant decrease in NE following the treatment with an RME $(p<0.001)$ with a reduction of number of wet nights per week from $5.48 \pm 1.48$ at baseline to $3.09 \pm 2.49$ after RME. This represented as $48.5 \%$ of the patients to be full or intermediate responders and $51.5 \%$ of the patients considered as non-responders.

Al-Taai et al. [25] did not use the previously mentioned terms of full, intermediate, and non-responders; instead, he reported that after RME expansion six out of 12 patients showed a complete dryness, and the remaining 6 patients showed an improvement in the NE. On the contrary, the control group (7 patients) showed no significant change in the frequency of their NE $(p>0.05)$. 


\begin{tabular}{|c|c|c|c|c|c|c|c|c|}
\hline \multicolumn{9}{|c|}{ Domain } \\
\hline Study & Domain 1 & Domain 2 & Domain 3 & Domain 4 & Domain 5 & Domain 6 & Domain 7 & Overall \\
\hline $\begin{array}{l}\text { Neveus et al, } \\
2014 \text { \& } \\
\text { Bazargani et al, } \\
2016\end{array}$ & & & & & & & & \\
\hline $\begin{array}{l}\text { Al-Taai et al, } \\
2015\end{array}$ & & & & & & & & \\
\hline $\begin{array}{l}\text { Hyla-Klekot et al, } \\
2015\end{array}$ & & & & & & & & \\
\hline
\end{tabular}
(i) Domain 1: Confounding
(ii) Domain 2: Selection of participants
(iii) Domain 3: Classification of interventions
(iv) Domain 4: Deviations from intended interventions
(v) Domain 5: Missing outcome data
(vi) Domain 6: Outcome measurements
(vii) Domain 7: Selection of results reported

FIgURE 2: Risk of bias assessment for the non-RCT studies included in the review.

\begin{tabular}{|c|c|c|c|c|c|c|}
\hline & \multicolumn{7}{|c|}{ Domain } \\
\hline Study & Domain 1 & Domain 2 & Domain 3 & Domain 4 & Domain 5 & Overall \\
\hline $\begin{array}{l}\text { Jönson Ring } \\
\text { et al, 2019 }\end{array}$ & & & & & &
\end{tabular}

(i) Domain 1: Bias arising from the randomization process

(ii) Domain 2: Bias due to deviations from the intended interventions

(iii) Domain 3: Bias due to missing outcome data

(iv) Domain 4: Risk of bias in measurement of the outcome

(v) Domain 5: Risk of bias in selection of the reported result

FIGURE 3: Risk of bias assessment for the RCT study included in the review.

Finally, Hyla-Klekot et al. [27] described the intensity level of $\mathrm{NE}$ using a 4-grade scale, where a score of 4 = bedwetting twice a night, $3=$ once a night, $2=$ once or twice a week, and $1=$ once or twice a month. After the RME treatment, $10 / 16$ patients were completely dry, and this remained so 3 years later. 5/16 patients had their frequency decreased by one or two grades and 1 child did not improve at all.

3.3.2. Nasopharyngeal Airway Changes. Bazargani et al. [23] and Nevéus et al. [24] obtained a polysomnographic registration along with rhinomanometry and acoustic rhinometry to measure nasal airway patency, airflow, and oxygen saturation. They demonstrated a significant increase in nasal volume and airflow after treatment with the RME $(p=0.012)$. In addition, they reported a statistically significant association between a decrease in the enuresis and an increase in nasal volume $(p=0.034)$, but they could not detect such an association between a reduction in the enuresis and an increased nasal airflow $(p=0.46)$ [23].
Furthermore, Nevéus et al. [24] reported a resolution of the snoring habits as well as a greater nasal volume in the individuals who were treated with the RME.

Al-Taai et al. [25] further investigated airway dimensional changes using a coronal section of computed tomography (CT) scan of the sinuses as well as anterior rhinometry measurements to assess nasal airflow and resistance. They concluded that nasal airflow increased significantly $(p<0.001)$ with nasal airflow rising from $405.05 \mathrm{~cm} 3 / \mathrm{s}$ before the expansion to $584.86 \mathrm{~cm} 3 / \mathrm{s}$ following the expansion. The CT scans taken also showed a significant increase $(p<0.001)$ in the width of the nasal cavity at the level of the inferior concha and a significant decrease $(p<0.001)$ in the nasal airway resistance after the expansion with the RME compared to prior to the expansion.

3.3.3. Psychological Impact and Sleep Disorders. Most of the studies highlighted that persisting NE was a high risk of psychosocial comorbidity and negatively affects the quality of life. The feeling of helplessness of enuretic patients highlights 
the magnitude and complexity of the problem. Persisting enuresis adversely affects the coping, social competence, and school performance of enuretic patients when compared to their normal peers. Furthermore, a negative correlation exists between the self-esteem of an enuretic child and the chance of treatment failure $[12,23,26]$.

Furthermore, a considerable number of enuretic patients was found to have concurrent sleep problems, including but not limited to snoring and sleep apnea. Elimination of airway obstruction at nasopharyngeal or oropharyngeal level with either tonsillectomy or adenoidectomy or both may improve the nocturnal enuresis, and it showed favorable results $[9,23,25]$.

It is worth mentioning that many of our included studies have excluded patients who have any concurrent urological, endocrinological, nephrological, odonatological, or psychiatric disorders.

3.3.4. Expansion and Retention. The expansion device used in our included studies was the RME expansion device with hyrax screw soldered to orthodontic bands on the upper permanent first molars. However, Al-Taai et al. [25] also applied bands on the first premolars or second primary molars of patients who had an unerupted first premolars.

Retention after expansion was done by leaving the same appliance in situ for a few months $[23,24]$ or by using a Hawley retainer [25]. However, Hyla-Klekot et al. [27] did not elaborate on the method of expansion and retention.

Follow-up period ranged from 6 months to 3 years. At least 6 months of follow-up was required post expansion for a study to be included in our systematic review. The followup assessment was done by either phone or direct interviews [24].

3.3.5. Occlusion. Investigating changes in occlusion brought about by RME devices was not the primary objective in the studies included in this systematic review. However, most studies obtained dental casts to check occlusion along with intermolar, interpremolar, and intercanine distances. They revealed that occlusion characteristics did not affect the outcome. Furthermore, it was found that the RME device can be used as an alternative method to improve the NE in patients with a normal bucco-lingual relationship of the posterior teeth with no detriment to the occlusion [23].

It was noticeable that reporting changes in occlusion was not consistent between studies. Hyla-Klekot et al. [27] reported the percentages of malocclusion and unilateral or bilateral crossbites in the patients included in the study. They showed that the most common malocclusion was a class II (35\%) which was often associated with the presence of a deep bite $(33 \%)$, whereas a posterior crossbite was reported in $14 \%$ of the individuals. The least common malocclusions were the class III (4\%) and the open bite $(2 \%)$. They concluded that the main aim of RME treatment was not to correct the malocclusion but to only reduce the NE. Similarly, Bazargani et al. [23] reported percentages of malocclusions and crossbites. Only two of the 34 subjects included in their study had posterior crossbites; 26 patients (76\%) had an Angle Class I, which included the two crossbite cases; 7 (21\%) had an Angle Class II with a mean overjet of $5.6 \mathrm{~mm}$; and $1(3 \%)$ had an Angle Class III. They concluded that no untoward impact could be observed on the occlusion in the long-term, thus corroborating the above finding that patients with normal occlusal features can be treated with a rapid maxillary expansion to improve their NE condition. Al-Taai et al. [25] reported patients with different degrees of crowding and only 2 out of 19 patients had a crossbite. They did not report on the skeletal class or Angle classification of their sample.

Such a variation in reporting occlusal changes was expected since the primary focus of the studies included in this review was the effect of an RME on the nocturnal enuresis.

3.4. Evaluating the Strength of Evidence Provided by This Review. The overall quality of evidence provided by this review for the main outcome measure, i.e., a decrease in the number of wet nights/week following the treatment with an RME device, was found to be very low. This was due to the moderate to critical risk of bias across the included studies except one, which was of low risk of bias, small sample sizes investigated by the majority of studies, and non-significant findings from a clinical point of view (Table 2).

\section{Discussion}

NE is a stressful condition that affects the child's emotional wellbeing immensely which further reflects on their quality of life, self-esteem, and school performance; such drawbacks can significantly improve with a successful treatment [11]. It has been reported that NE have an annual spontaneous cure rate of $15 \%$ [6] and up to date, there is no clinically approved treatment modality for the NE condition in patients, where all commonly used treatments can only produce slight improvement and thus are considered of minimal efficacy. Therefore, investigators have started focusing on alternative treatment options. One of the possible suggested causes of $\mathrm{NE}$ is an upper airway obstruction [9]. Moreover, up to $80 \%$ of enuretic patients have concurrent sleep apnea [13]. Thus, it was only logical to consider palatal expansion as a potential solution to NE in young patients.

In this systematic review, we found that the most commonly used and effective device for expansion is the RME device with a hyrax screw soldered to orthodontic bands on the first permanent molars. This orthodontic device results in expansion of the maxilla due to separation of the mid palatal suture over a period of 10-14 days where the midline screw was activated twice daily to achieve a total daily expansion of $0.5 \mathrm{~mm}$ [23-27]. The endpoint of expansion was concluded as when the occlusal surfaces of the palatal cusps of the upper first permanent molars came into contact with the occlusal surfaces of the buccal cusps of the lower first permanent molars [23-26].

Although examining the effect of RME on occlusion was not a primary objective in our review, it is worth mentioning that the RME device can be used as an alternative method to improve the NE condition in patients with a normal 


\section{Conflicts of Interest}

The authors have no conflicts of interest to declare.

\section{References}

[1] M. R. Järvelin, L. Vikeväinen-tervonen, I. Moilanen, and N.-P. Huttunen, "Enuresis in seven-year-old children," Acta Paediatrica, vol. 77, no. 1, pp. 148-153, 1988.

[2] W. F. Bower, K. H. Moore, R. B. Shepherd, and R. D. Adams, "The epidemiology of childhood enuresis in Australia," BJU International, vol. 78, no. 4, pp. 602-606, 1996.

[3] A. von Gontard, J. Heron, and C. Joinson, "Family history of nocturnal enuresis and urinary incontinence: results from a large epidemiological study," Journal of Urology, vol. 185, no. 6, pp. 2303-2307, 2011.

[4] P. F. Austin, S. B. Bauer, W. Bower et al., "The standardization of terminology of lower urinary tract function in children and adolescents: update report from the standardization committee of the International Children's Continence Society," Neurourology and Urodynamics, vol. 35, no. 4, pp. 471-481, 2015.

[5] K. Hja"lma 's, T. Arnold, W. Bower et al., "Nocturnal enuresis: an international evidence based management strategy," Journal of Urology, vol. 171, pp. 2545-2561, 2004.

[6] W. I. Forsythe and A. Redmond, "Enuresis and spontaneous cure rate: study of 1129 enuretics," Archives of Disease in Childhood, vol. 49, no. 4, pp. 259-263, 1974.

[7] R. A. Hirasing, F. J. M. van Leerdam, L. Bolk-Bennink, and R. A. Janknegt, "Enuresis nocturna in adults," Scandinavian Journal of Urology and Nephrology, vol. 31, no. 6, pp. 533-536, 1997.

[8] P. van Kerrebroeck, P. Abrams, D. Chaikin et al., "The standardisation of terminology in nocturia: report from the standardisation sub-committee of the International Continence Society," Neurourology and Urodynamics, vol. 21, no. 2, pp. 179-183, 2002.

[9] D. J. Weider and P. J. Hauri, "Nocturnal enuresis in children with upper airway obstruction," International Journal of Pediatric Otorhinolaryngology, vol. 9, no. 2, pp. 173-182, 1985.

[10] H. Eiberg, H. L. Shaumburg, A. von Gontard, and S. Rittig, "Linkage study of a large Danish 4-generation family with urge incontinence and nocturnal enuresis," The Journal of Urology, vol. 166, pp. 2401-2403, 2001.

[11] P. H. Y. Caldwell, A. V. Deshpande, and A. V. Gontard, "Management of nocturnal enuresis," BMJ, vol. 347, p. f6259, 2013.

[12] W. L. M. Robson, "Evaluation and management of enuresis," New England Journal of Medicine, vol. 360, no. 14, pp. 1429-1436, 2009.

[13] J. G. Barone, C. Hanson, D. G. DaJusta, K. Gioia, S. J. England, and D. Schneider, "Nocturnal enuresis and overweight are associated with obstructive sleep apnea," Pediatrics, vol. 124, no. 1, pp. e53-e59, 2009.

[14] J.-E. C. Holty and C. Guilleminault, "Maxillomandibular expansion and advancement for the treatment of sleep-disordered breathing in children and adults," Seminars in Orthodontics, vol. 18, no. 2, pp. 162-170, 2012.

[15] C. M. Glazener, J. H. Evans, and R. E. Peto, "Alarm interventions for nocturnal enuresis in children," Cochrane Database of Systematic Reviews, vol. 18, 2005.

[16] D. J. Timms, "Rapid maxillary expansion in the treatment of nocturnal enuresis," The Angle Orthodontist, vol. 60, no. 3, pp. 229-234, 1990.
[17] J. Kurol, H. Modin, and A. Bjerkhoel, "Orthodontic maxillary expansion and its effect on nocturnal enuresis," The Angle Orthodontist, vol. 68, pp. 225-232, 1998.

[18] U. Schütz-Fransson and J. Kurol, "Rapid maxillary expansion effects on nocturnal enuresis in children," The Angle Orthodontist, vol. 78, no. 2, pp. 201-208, 2008.

[19] J. A. Sterne, M. A. Hernán, B. C. Reeves et al., "ROBINS-I: a tool for assessing risk of bias in non-randomised studies of interventions," BMJ, vol. 355, p. i4919, 2016.

[20] J. P. Higgins, D. G. Altman, P. C. Gøtzsche et al., "The Cochrane Collaboration's tool for assessing risk of bias in randomised trials," BMJ (Clinical Research Edition), vol. 343, no. 182, p. d5928, 2011.

[21] G. H. Guyatt, A. D. Oxman, G. E. Vist et al., "GRADE: an emerging consensus on rating quality of evidence and strength of recommendations," BMJ, vol. 336, no. 7650, pp. 924-926, 2008.

[22] K. Poorsattar-Bejeh Mir, A. Poorsattar-Bejeh Mir, M. Poorsattar-Bejeh Mir, M. Moradi-Lakeh, P. Balmeh, and K. Nosrati, "Rapid palatal expansion to treat nocturnal enuretic children: a systematic review and meta-analysis," Journal of Dentistry, vol. 16, no. 3, pp. 138-148, 2015.

[23] F. Bazargani, I. Jönson-Ring, and T. Nevéus, "Rapid maxillary expansion in therapy-resistant enuretic children: an orthodontic perspective," The Angle Orthodontist, vol. 86, no. 3, pp. 481-486, 2015.

[24] T. Nevéus, L. Leissner, S. Rudblad, and F. Bazargani, "Orthodontic widening of the palate may provide a cure for selected children with therapy-resistant enuresis," Acta Paediatrica, vol. 103, no. 11, pp. 1187-1191, 2014.

[25] N. Al-Taai, F. Alfatlawi, M. Ransjö, and S. Fakhry, "Effect of rapid maxillary expansion on monosymptomatic primary nocturnal enuresis," The Angle Orthodontist, vol. 85, no. 1, pp. 102-108, 2015.

[26] I. J. Ring, T. Nevéus, A. Markström, A. Magnuson, and F. Bazargani, "Rapid maxillary expansion in children with nocturnal enuresis: a randomized placebo-controlled trial," The Angle Orthodontist, vol. 90, no. 1, pp. 31-38, 2019.

[27] L. Hyla-Klekot, M. Truszel, A. Paradysz, L. Postek-Stefańska, and M. Życzkowski, "Influence of orthodontic rapid maxillary expansion on nocturnal enuresis in children," BioMed Research International, vol. 2015, pp. 1-7, 2015. 